\title{
MATERNAL IDENTITY OF WOMEN IN THE POSTPARTUM PERIOD
}

\author{
Maria B. Perun \\ maria_gera@yahoo.com \\ Ivan Franko Lviv National University, \\ Ukraine
}

\begin{abstract}
The article provides a theoretical analysis of the notions of "maternity", "maternal sphere", "maternal role" and "maternal identity". The place of maternal identity in the system of a woman's identities is determined. This article provides a brief description of the structural elements (cognitive, emotional, behavioural and axiological) of maternal identity. It also emphasizes the significance of the postpartum period in a women's psychic life and stresses its pivotal role in the development of maternal identity. Finally, the article points out some peculiarities of maternal identity of full-term and pre-term mothers.
\end{abstract}

Key words: maternal identity, postpartum period, stages of maternity, full term infants, preterm infants.

The period of early adulthood is characterized by a number of peculiarities which relate to attaining new social roles, reaching maturity and overcoming crisis periods. The same stages are relevant within the context of studies of maternity. When a woman becomes a mother, she attains a new social role - that of a mother. By internalizing it, a woman reaches a new level of maturity and maternal identity.

The purpose of this article is to highlight and analyze the notion of maternal identity by (1) defining and separating such notions as "maternity", "maternal sphere", "maternal role", "maternal identity"; (2) determining the place maternal identity occupies within the system of women's identities; (3) providing short characteristics of the structural elements of the phenomenon in question; (4) identifying key phases and stages of the development of maternal identity; (5) describing the role of the postpartum period in a woman's psychic life; and finally, by pointing out some possible peculiarities of maternal identity of women after a full-term and pre-term pregnancy.

\section{MATERNAL IDENTITY AS A PSYCHOLOGICAL PHENOMENON}

Modern literature defines maternity as a complex bio- and psycho-social phenomenon, or, more specifically, the result of the interaction of numerous factors, genetic, biological and those pertaining to the family and social environment. The phenomenon of maternity is predicated on physiological mechanisms, evolution history and cultural and individual peculiarities. Without fully innate mechanisms, it is based on the biological need for maternity, which, in turn, is transformed by in- 
teriorized social norms (Filippova, 2002). Maternity as a psycho-social phenomenon is addressed from two main positions: as provision of conditions for the development of a child (main tasks of works and their interpretation goes from the tasks of child upbringing to mother's peculiarities) and as part of a personal sphere of a woman (maternity is studied in terms of a woman's contentment with her maternal role and as a stage of personal and gender identification).

Galyna G. Filippova (2002) suggests that maternity should be accepted as a part of a woman's personal sphere that has a phylo- and ontogenetic history oriented towards fulfilling the tasks of child birth and upbringing. Also, she views maternity not only as a stage of child development but also as a peculiar maternal need and motivational sphere (hereafter mentioned as maternal sphere) of a woman's psychic life that is formed throughout one's life. Fundamentals of future maternity are laid down in the early childhood of a girl. Then, they are formed by way of interactions with her own mother (or a person who acts as one), game activities, personal experience of communication with small kids and are realized during pregnancy and with interactions with one's own child.

The concept of the maternal sphere was formulated by Daniel Stern. He suggested the term "motherhood constellation" to interpret the maternal experience which occurs at the end of pregnancy period and is being shaped during the early stages of motherhood. The author draws attention to the fact that this psychic formation temporarily becomes central and replaces the previous ones. In his opinion, the maternal sphere is formed through four mutually related thematic tasks. Of these four tasks, the last one is called "identity reorganization". It requires the mother to transform and re-establish her identity (Stern, 1995).

Oksana B. Podobina (2005) indicates that as a mother, a woman occupies a new position in the system of social relations and attains a new social role - that of a mother. Accepting the role of a mother by a woman entails the beginning of a real role behaviour, an adjustment of parental attitudes of a woman. Her ideas about herself as a mother, social expectations of the people around her, restructuring of role palette of a person, an appearance or actualization of the need to be a mother and restructuring of personal sense.

Edit Bibring is of the opinion that pregnancy can be considered as a stage in the development of a new social role - that of a mother. It is assumed that pregnancy, labour and maternity both mean a successful acceptance of the new role of a mother and represent certain stages of mature women's identity formation. The more complete the previous stage is, the more successful the one that follows will be.

Noel Blackburn leans toward the idea that pregnancy and the early period that follows giving birth to a child is the period of major "psychological upheaval" in a woman's life, which results in the formation of maternal identity (Blackburn, 2006, p. 21). The subject of maternal identity has been addressed by many authors. Reva Rubin (1975), for instance, defines it as an internal feeling of a woman: the recognition that she is competent as a mother as well as her knowledge and understanding of her child. In Galyna S. Shewtchuk's (2010) understanding, maternal identity constitutes a psychological construct through which a woman expresses her complex perception, awareness and experience of being a mother, as well as her personal 
self-realization in maternity. The researcher points to the fact that maternal identity is a central formation of the maternal need, a motivational sphere and axiological processes when a woman begins to identify herself with her new role as a mother.

Thus, correlation of such notions as maternity, maternal sphere, mother's role and maternal identity can be seen in the following way. Maternity is a bio-psycho-social phenomenon that is reflected in the psychic life of women within a maternal sphere. Formation of the maternal sphere is a lifetime process, whose basics are laid down in a girl's early childhood. The core of maternal sphere is maternal identity of a woman, which is established on condition that woman accepts the social role of a mother.

Joel Block was one of the first to stress the fact that mothers approach maternity with an already existing identity. She contends that self-perception of a woman undergoes transformations; gradually, the woman integrates her identity as a mother into her general (global) identity. With her experience being changed, which is connected with maternity, she still remains within the context of her previous experience: before becoming a mother who depends on her child, she was a woman. The balance between these two identities depends on the individual features of a woman. Identity crisis accompanying maternity is resolved when a new understanding of oneself is perceived as more significant than any of the previous ones and a woman under this new condition feels in harmony with herself (cited in Blackburn, 2006, p. 11-12).

The results of our research show that during the first three months of an infant's life, the system of women's identities includes the following components: family and the maternal "I", I-person, the female "I", the social "I", "I" a housekeeper as well as a global self-perception. In this period, particularly important life spheres for women are those related to family life and the realization of their maternity. Three out of six structure components include the indicators that show an attitude to one's maternity or perceiving oneself as a mother. Of interest and great importance is the fact that the indicators reflecting maternal and spouse identities are closely related. It is suggested, then, that in such an early period of maternity there is no strict separation of these two identities. A woman who - before giving birth to a child - was performing the role of a wife and only imagined herself as a mother does not separate these roles. On this basis one can assume that a harmonious family life, contentment in marriage and a husband's support can be instrumental in developing maternal identity in the postpartum period. On the other hand, we have revealed that one's perception as a daughter, sister, friend or employee does not conflict with the maternity situation and does not lead to an overconcentration on one's child. During infancy a mother and her child are isolated from the influence of their surrounding environment and this somehow restricts the social contacts of the woman. However, the harmonious development of a woman's social interrelations of women before labour, her various social roles and their perception also contributes both to her understanding of the new role - that of a mother and the development of maternal identity (, 2011).

Thus, identifying the place maternal identity occupies within the system of woman's global identity, we consider it to be an element that appears at a certain stage of a woman's life, which, as we argue, is the postpartum period. Depending on the social situation, maternal identity can be in the centre of the system (identification matrix 
of a woman's personality) (Shewtchuk, 2010, p. 775). At the same time, this complex dynamic system of interrelated identity types is different for different people.

While analyzing the structure of maternal identity, we see that the majority of authors tend to distinguish a three-component structure of maternal identity. We shall consider each of these three components - cognitive, emotional and behavioural - as well as an axiological component, distinguished by G. S. Shewtchuk.

The "cognitive component" of maternal identity includes the system of a woman's conscious and unconscious knowledge of her role as a mother: the main characterological features, knowledge about the functions of a mother, her behaviour and attitudes towards caretaking and upbringing. This system of knowledge is dynamic and is in the process of development throughout a woman's life. It can demonstrate a clear hierarchy, be harmonious and flexible or can be poorly structured and contradictory. The steps that a mother undertakes before the baby is born are every woman's individual choice. Some are preparing for this moment for many years, others understand that they are pregnant but so far do not feel any desire to become a mother. Their level of knowledge about children also differs a lot. However, the cognitive component is being formed much earlier, and it precedes the stage at which a woman starts thinking about her future role of a mother. Thus, it is possible to conclude that any woman who has given birth to a child at the moment of child's birth already possesses some knowledge about her new-born baby. Soon, a mother will acquire some specific knowledge about her baby. Even before the child has been accepted by its mother, the cognitive component is already part of the process of formation of maternal identity. The maturity of this element can be expressed in the fact that a mother already has a necessary knowledge about a child. Moreover, she not only possesses an external knowledge but also an intuitive one: she has abilities to understand her child's needs as well as signals a child sends at the prenatal stage.

The "affective component" of maternal identity includes an emotional attitude of a woman to the system of knowledge related to maternity: her feelings about herself as a mother, her positive and negative features, actions, deeds related to maternity, experiencing the self-value of maternity. It is necessary to stress that maternity should be understood in a broader sense than as a system of relationships between mother and child. For instance, maternity embraces issues connected with a woman making a decision about giving birth to a second/third child or her evaluation of her own capabilities to combine maternity with her professional career as well as other problems which also belong to the maternity sphere but go beyond purely child's interests in the "mother-child" relation. Here also those elements that are related to perceiving a child on the level of emotions and subconsciousness come into play: an intuitive knowledge about children as well as dreams, fantasies about how the mother wants to see her child now and in future. This emotional component is expressed with full awareness of a child as a value in itself. The child becomes a means of its mother's self-realization or keeping its mother's partner in the family.

The "behavioural component" of maternal identity is defined by a mother's behaviour in her relationships with a child. It includes an active demonstration of the content of maternal identity: a woman's behaviour that is aimed at the realization of herself as a mother and at improving personal qualities, skills and abilities related 
to maternity. Significantly, the behavioural component is closely related to the cognitive and emotional ones. Since at the moment a child is born, there already exists certain knowledge, then what is of importance is the process of perceiving a child and feeling oneself like a mother who experiences certain emotions. However, these emotions will differ, depending on whether the mother has given birth to a healthy child or a child with some dysfunctions. Following this logic, the behaviour of mothers having healthy children and those having unhealthy children will also be different. The maturity of this component is expressed in competent interrelations of a mother and her child, adequate to her needs; an ability to make responsible choices.

The "axiological component" of maternal identity is represented by a cluster of value orientations which are formed in the process of gaining social experience related to maternity and which manifest themselves in aims, ideas, beliefs and an interest in the maternity sphere. This value related and sense bearing aspect, together with the cognitive one, is an important factor of the social regulation of maternal behaviour. It is related to national and cultural as well as general and historical development of maternity values.

As we see, there is a microcirculation of information among all the discussed components. Changing one of them would in general result in a change of maternal identity.

\section{PECULIARITIES OF THE POSTPARTUM PERIOD IN A WOMAN'S MENTAL LIFE}

As previously mentioned, we consider the postpartum period to be an important one for the formation of maternal identity. This view is favoured by Mary Ainsworth, particularly in her conclusion about the paramount importance of the baby's first months of life in establishing mother-and-child interaction, and thus for the formation of a woman's maternal identity (cited in Craig, 2000, p. 302-307; Dobryakov, 2011, p. 140-141).

We think that it is important to draw attention to the fact that during this period women's physical and emotional state is very difficult, especially in the case of a woman's first labour. This stage is considered to be critical in a mother's life. It entails changes in her social status. These changes are associated with the establishment of her maternal identity. This causes difficulties in the acquisition of new skills related to childcare, the need to extend family and perceive herself in a new role of a mother. As the birth of a baby is an important event in the family life, in the postpartum period a woman experiences a wide range of emotions and feelings which in the long run could reflect her relationships both with the baby and other family members. All these changes will undoubtedly influence the formation of both maternal identity of a woman in general and every of its constituent elements in particular.

This period is marked and accompanied by numerous rules, rituals and beliefs in all cultures. The mother and child should always be more or less strictly isolated from the world and other people. Besides serving a hygienic purpose, this isolation has profound psychological meaning. The mother's whole existence at this point is being centered on the baby and her own experience associated with maternity. 
This period is characterized by a territorial integration with the baby (being with the baby as much as possible in terms of time and space); there are also specially established conditions for the mother, facilitating her positive feelings to reinforce this period's singularity for her life-time. Traditional and positive development of this period creates favourable conditions for ensuring the tool-associated actions for childcare and communication of the mother and baby. The mother learns to adequately react to her baby's motions; as a result, her individual style of childcare is being formed. Tactile contact with an infant is equally important. The mother should learn to correctly identify the baby's needs and organize her responses through use of an appropriate tone (confidence, care, tenderness). These qualities to a great extent depend on the mother's general maternal skills as well as on the peculiarities of her attitude to the baby.

Establishing a successful set of the mother-and-baby interactions matters not only for the development of a baby, but also for the formation of maternal identity of a woman. It is established through nonverbal communication by setting transmitting and emotional signals which to a great extent determine a further family education style and the type of a woman's maternal identity. Ihor V. Dobryakov's studies (2011) have shown that in the process of establishing an early relationship between mother and child of importance is the stage of family relations at which the conception, the pregnancy and the delivery occurred. In the case of the prenuptial conception, at the stage of either confrontation or experiments with independence, there arise difficulties in the formation of an early dialogue between mother and baby. Unresolved conflicts with a partner and his compensatory behaviour at these stages fill the woman with anxiety and make her emotionally unstable, which is reflected in her relationships with the baby. This state frequently leads to neurotic, unreasonable worries about the child's health or, at its extreme, to the fear of loss of the baby. Enormous problems in the relationship with the child arise when the child falls short of expectations placed on him/her. As a rule, upbringing of such a child is performed according to a type of hyperprotection and is characterized by an unconscious or conscious maternal rejection (Dobryakov, 2011).

\section{THE NOTION OF "ATTACHMENT" CONTRIBUTED TO THE RESEARCH ON MOTHER-AND-BABY RELATIONSHIPS.}

In his studies, John Bowlby showed that the establishment of warm and joyful relationship with the mother is absolutely essential for the psychological development of a child. He admitted that the "silver cord" connection is determined by the expressed need for the caring person to be closer. John Bowlby associates the development of psychic and motor functions of children with the development of methods designed to achieve close and warm relationships with their mothers. These relationships (meaning relationships between mother and child, proximity, closeness) ensure safety and allow researching, learning and adapting to new situations (Bowlby, 1969).

John Bowlby's theoretical assumptions were brilliantly confirmed by Mary Ainsworth's experiments. By observing babies during their first months of life, she tried 
to determine how the peculiarities of their relationships with mothers are revealed when the observed babies were breastfed, when they cried and when they were engaged in playing. The results of the research show that the mother-and-baby relationships are formed during the baby's first three months of living and determine the attachment character up to the end of the baby's first year and later. Mothers whose motions are synchronous with those of their babies, whose emotions are expressive and whose contacts are diverse, have a positive effect on the development of the child. On the contrary, less committed mothers, who rarely embrace their babies and suppress their emotions ("mothers with stiff faces"), do not facilitate the development of their children's psychical functions. Neither do the mothers who demonstrate inconsequent or unpredictable behaviour (cited in Craig, 2000, p. 302-306).

The above mentioned characteristics of the postpartum period testify to its profound importance and significance for the development of maternal identity of a woman. Stabilization of all concepts occurs (cognitive component of maternal identity), as well as the acceptance and development of operational content (behavioural component of maternal identity); the attitude towards the baby is specified; the emergence of feelings originating from the interaction with the baby forms the final concept of the need for maternity and childcare (emotional component of maternal identity); an interference of values acquire its stable meaning, being concretized under the conditions of neonatal period (value-related and sense bearing component of maternal identity).

\section{PRETERM LABOUR AND THE PECULIARITIES OF MATERNAL IDENTITY}

One of the trends in maternity study is investiging the peculiarities of mothers who are unable to adequately interact with their children at the first stage of the development of mother-baby interaction. This preterm separation could be caused by labour process abnormality, neonatal pathology or preterm labour.

Despite a growing interest in perinatal psychology, preterm labour as well as the peculiarities of the development of maternal identity under such circumstances still have not received the critical attention they merit. Olena Kuftyak notes that research related to the problem of preterm babies and their mothers is done mainly by experts in neuropsychiatry. In Ukraine, supervision over the preterm babies' development both during medical care and after their discharge from hospital is carried out solely by medical specialists. Preterm labour is a situation negatively affecting both sides: a mother and a child. Nevertheless, there have virtually been conducted no special studies of the psychic peculiarities of preterm mothers and their families in Ukraine.

In the case of the normal course of gestation and labour, a woman and her family have enough time and means to prepare both physically and mentally for upcoming changes. However, in the case of an abnormal situation, for example, preterm labour, everything is more complicated. For the parents, especially for the mother, the preterm birth of the baby may be emotionally a traumatic situation she has not been prepared for. Therefore, it is of great important to carry out studies of the peculiarities of women's maternal identity under such unusual circumstances. Awareness of 
these peculiarities will facilitate the process of women's adaptation to their new role as mothers, the process of accepting their babies and will become a basis of positive resources for them.

In the case of preterm labour before the end of the full 37-week period of pregnancy, the baby is treated as premature if its weight does not exceed $2500 \mathrm{~g}$ and its length is not over $48 \mathrm{~cm}$. According to various authors, the frequency of premature birth ranges from $3 \%$ to $16 \%$. As O. Kuftyak stresses, premature labour may leave the mother in a state of shock and, as a consequence, disturb her psychic defense activity, which deprives her of the possibility to apply the adaptive strategies of overcoming this critical situation. This state of shock could also go hand in hand with a feeling of guilt ("what have I done...?"), anger ("It's not fair"), rejection of the situation ("this is not happening to me") and depression ("I don't care").

Using the attitude to pregnancy test, Catherine Gron and Patima Imanaliyeva discovered that women at high risk of miscarriage are more prone to show euphoric and denying types of attitude to pregnancy. According to I. Dobryakov's studies, among women who give birth to preterm infants, euphoric, denying and anxious types of attitude to pregnancy prevailed, and the optimum one was observed four times more rarely than among women with term babies (Dobryakov, 2011, p. 135).

It is worth mentioning that the results of the study of the feelings of preterm babies' mothers are contradictory. They frequently point to the stereotype that has been created of the "preterm" baby, which is composed of a complex of cognitive, affective and behavioural patterns of the parents' and others' attitude to the preterm infant. First of all, it manifests itself in the parents' evaluation of the general medical condition of their child. Thus, the health of a preterm chid is considered to be more delicate. Parents are inclined to think that their child, until it turns 6 or 7, is more delicate and sensitive when compared to other children of the same age. There are data on the extension of this phenomenon onto other grown-ups, relatives and medical personnel as well (Lukovtseva \& Baz, 1999).

In our opinion, the impact of this stereotype may be related not only to the preterm baby, but also to its mother and family. This could influence the emotional state of a woman as well as the peculiarities of her perception of motherhood and formation of mature maternal identity.

Zoya Lukovtseva and Lyudmyla Baz (1999) have discovered that there is a wide range of circumstances under which the adverse effect of prematurity is neutralized (e.g. the character of interaction between mother and child could influence it). They also state that the differences between full-term and preterm babies may be less obvious in the case of preterm children who are raised in families having emotional resources to compensate for disruption of interaction with babies. If preterm babies, especially those at high biological risk, are brought up in families at social risk and are insufficiently included in direct interaction with mothers, they may suffer from an emotional disturbance. In this context, I. Dobryakov (2011) points out that even if a baby is born full-term and healthy, an incorrect performance of childcare during the early postnatal period may lead to a chronic post trauma situation which will, in turn, entail the lowering of both a separation anxiety level and bonding formation. As a result, there may occur the disruption of adaptive processes, kenogenesis and 
psychomotor delays. Thus, we may trace the influence of a woman's maternal identity on the child's development and vice versa.

After preterm labour, the psychological problems related to women's maternal identity formation may also be caused by the lack of physical contact with the baby which has to undergo a medical treatment at ITU in the meantime. Researchers emphasize that lack of eye contact between mother and child and limited sensational contact make the mother's perception of the baby substantially virtual (Yesenina, 2003). Such a situation not only will not ensure the necessary conditions for the maternal identity formation in but will also lead to their deterioration, which may pose a threat to the baby. In such cases, it is possible that the mother will be less willing to keep close to her baby (emotional component of maternal identity) and there may be disorders in breastfeeding (behavioural component of maternal identity). Inconsequent behaviour of the preterm baby caused by its special needs could dismay and frustrate its parents: they may feel anxious about the problems of survival and development of the child. As a result, they either avoid the baby or compensate the changes of preterm infants' behaviour with hypercare. Irrespective of the inconsistency of their behaviour, parents overstimulate their baby even more, exacerbating its behaviour and increasing their own frustration (Lukovtseva \& Baz, 1999). Thus, the preterm infant and the problems it entails may drain the emotional resources of a number of mothers and, as a consequence, may have a negative impact on the formation of a woman's maternal identity.

The conducted empirical study of mothers in the postpartum period has shown that irrespective of whether a woman gave birth to a preterm or full-term infant, her attitude toward pregnancy could be identical. Yet the risk group includes more mothers after preterm labour. Mothers' self-concept, their attitude to family roles and babies, and their family life satisfaction are important factors influencing women's attitude to pregnancy (Perun, 2011b).

Regarding the self-attitude of the mothers who participated in the study, three groups of women have been distinguished: those inclined to adopt apositive self-attitude, those inclined to a markedly positive self-attitude and those inclined to a non-differentiated self-attitude. The majority of the subjects (44\%) tend to adopt a positive self-attitude. Among them, mothers of both preterm and full-term babies make two almost equal groups. The women in this group are liable to an insignificant emotional distance from their babies. Some important factors for the development of their positive self-attitude are family life satisfaction as well as the feeling of protection and love they received from their own mothers. A markedly positive self-attitude is typically attributed to mothers with full-term infants rather than those with preterm ones. These women are characterized by close emotional contact with their babies. Just like the previous group, they also received support, love and care from their mothers. The women in the last group, which was incidentally the least numerous, tend to have a non-differentiated self-attitude, and among them prevail mothers with preterm babies. They are the least self-satisfied among the subjects and they are inclined to distance themselves from the baby. However, family life satisfaction and their own mother's care under certain circumstances could neutralize these factors (Perun, 2011c). 
There have been no significant differences in the emotional attitude to maternity among the mothers of full-term and preterm babies. The study allowed to distinguish three emotional attitudes of women to maternity: those inclined to a positive attitude with poor emotional contact with the baby, those inclined to a positive attitude with good emotional contact with the baby and those inclined to a controversial emotional attitude to maternity. Positive emotional attitude and poor emotional contact with the baby is predominantly more characteristic of the mothers with full-term infants $(54.2 \%)$ than of those with preterm ones (45.8\%). The majority of the subjects $(59.2 \%)$ are inclined to adopt a positive emotional attitude to maternity and to maintain good emotional contact with the baby. Among them prevail mothers who have given birth to preterm babies $(64.7 \%)$. The smallest group of the participants is characterized by its controversial emotional attitude to maternity, and in this group prevail mothers with preterm infants (64.5\%) (Perun, 2011a). Thus, regardless of whether a woman gave birth to a full-term or preterm baby, her emotional attitude to maternity may be identical.

\section{CONCLUSIONS}

Maternal identity is understood as the perceptual unity of self-perception, consciousness and feeling of a woman as mother as well as her own self-realization of maternity. The woman-mother identity is inseparable from her global identity. One can say that maternal identity is a constituent of the global identity of a woman who, at a certain stage of her life, may become dominant or even essential. We think that the postpartum period is the stage in question.

The development of this type of identity takes a woman her whole life. The foundations for this kind of identity are already laid in childhood and are later formed in youth. However, it is during pregnancy and upon the birth of her first child that a woman gives identifies herself as a mother. The concept of maternal identity differs from woman to woman. It depends on how complete the structural elements of maternal identity (cognitive, behavioural, emotional and axiological) are. Maternal identity, as well as any other identity type, is not a stable phenomenon and can alter throughout a woman's life. However, the formation of a positive type of maternal identity at the early stages of mother-and-baby interaction is a necessary precondition for its further establishment. The ambiguousness of data presented in the literature on the topic has brought us to the idea that maternal identity of women giving birth to either full-term or preterm infants differs. We see the follow-up studies as an investigation of human personalities of mothers after preterm labour.

\section{REFERENCES}

Blackburn, N. (2006). Identity and the new mother. Unpublished partial fulfilment for doctoral dissertation, Faculty of the Institute for Clinical Social Work, Chicago. Retrieved from http:/ / www.yumpu.com/ en/document/view/4704026/identity-and-the-new-mother-institute-for-clinical-social-work.

Bowlby, J. (1969). Attachment and loss (Vol. 1). New York: Basic Books.

Brutman, V. J., Filippova, G. G., Chamitova, I. J. (2002). The dynamics of the psychological state of women 
during pregnancy and after birth. Questions of Psychology, 3, 59-68.

Craig, G. (2000). Developmental Psychology. St. Petersburg: Питер.

Dobryakov, I. V. (2011). Perinatal Psychology. St. Petersburg: Питер.

Yesenina, Y. I. (2003). On some notions of ontogenesis of basic qualities of a mother. Perinatal Psychology and Parental Psychology, 4-5, 49-63.

Filippova, G. G. (2002). Psychology of motherhood. Moscow: Изд-во Института Психотерапии.

Knyazeva, A. P. (2009). The Comparative Analysis of Affective and Behavioural Components of Parental Identity of Mothers of Healthy Children and Children with Development pathology. Yaroslavskyy pedagogical Journal, 4, 173-177.

Kuftyak, O. V. (2012). Premature birth and a woman: the socio-psychological aspects. Retrieved from: http:/ / www.psyinst.ru/library.php?part=article\&id=1919.

Lukovtseva, Z. V., Baz, L. L. (1999). Mental development of premature infants. Questions of Psychology, 6, 29-35.

Perun, M. B. (2011a). Typology of Emotional Attitude of Women to Maternity. Practical Psychology and Social Work, 6 (143), 11-16.

Perun, M. B. (2011b). Social and Psychological Factors of Attitude to Pregnancy of Term and Preterm Babies Mothers, Regional Education: Political Studies, Psychology, Communications. Ukrainian Scientific Journal, 3, 266-271.

Perun, M. B. (2011c). Psychological Peculiarities of Mothers with Positive and Non-differentiated Selfattitude. Issues of General and Pedagogical Psychology, Vol. XIII, Part 3, 302-310.

Perun, M. B. (2012). Maternal identity in the system of women identities. Issues of General and Pedagogical Psychology, XIV Part 2, 290-297.

Podobina, O. B. (2005). Coping behavior of women at the stage of being a mother. Unpublished Autoreferat of PH.D. dissertation. St. Petersburg.

Rubin, R. (1967). Attainment of the maternal role. Part 1: Processes. Nursing Research, 16, 237-245.

Shewtchuk, G. S. (2010). Maternal identity in structure Self-conception of women. Problems of modern psychology, 9, 765-777.

Stern, D. (1995). The motherhood constellation. New York: Basic Books. 